\title{
Preventieve steun aan 6-8 jarige kinderen van gescheiden ouders: hoe succesvol is het groepsprogramma Dappere Dino's?
}

\author{
M. Klein Velderman · F.D. Pannebakker · S.A. Reijneveld
}

Published online: 27 March 2015

(C) Bohn Stafleu van Loghum 2015

\begin{abstract}
Samenvatting Jaarlijks zijn naar schatting 70.000 thuiswonende Nederlandse kinderen betrokken bij de scheiding van hun ouders. Onderzoek toont aan dat scheidingskinderen gemiddeld minder presteren op school, meer gedragsproblemen vertonen en lager scoren op sociaalemotioneel vlak. Preventief hulpaanbod ter ondersteuning van deze kinderen is beperkt, vooral voor kinderen tot 8 jaar. In een pilotonderzoek van 26 kinderen, verdeeld over zes interventiegroepen werd onderzocht of met de preventieve groepsinterventie Dappere Dino's scheidingskinderen van 6-8 jaar succesvol ondersteund kunnen worden. Proces en impact van de interventie werden geëvalueerd door gesprekken met deelnemende kinderen en vragenlijsten door ouders, leerkrachten en trainers. Kinderen hadden naar eigen zeggen nieuwe vrienden gemaakt, geleerd problemen op te lossen en te praten over gevoelens. Ook ouders waren enthousiast. Ouders zagen een positieve reactie bij hun kind en vonden dat hun kind positief veranderd was na de interventie. Trainers werkten graag met het programma. Bovendien bleek uit de verschillen tussen voor- en nameting een toename in positief functioneren van de kinderen en een afname van problematiek (minder emotionele problemen, gedragsproblemen en totale problemen). De gevonden resultaten vormen de basis voor verdere implementatie van de interventie in de praktijk, en voor voortgaand effectonderzoek naar de uitkomsten van de interventie.
\end{abstract}

Trefwoorden Preventie - Basisschool - Echtscheiding · Dappere Dino's · Groepsinterventie

\author{
M. Klein Velderman $(\bowtie) \cdot$ F.D. Pannebakker \\ Afdeling Jeugd, TNO, \\ Leiden, Nederland \\ E-mail: Mariska.kleinvelderman@tno.nl \\ S.A. Reijneveld \\ Sociale Geneeskunde, Universitair Medisch Centrum Groningen, \\ Groningen, Nederland
}

\section{Inleiding}

In Nederland zijn naar schatting jaarlijks $70.000(1,75 \%)$ thuiswonende kinderen bij de scheiding van hun ouders betrokken [1]. Onderzoek heeft herhaaldelijk laten zien dat kinderen negatieve gevolgen ondervinden van de scheiding van hun ouders [2]. Een meta-analyse van Amato en Keith [3] toont aan dat scheidingskinderen gemiddeld minder presteren op school, meer gedragsproblemen vertonen en lager scoren op sociaal-emotioneel vlak.

Ondanks genoemde risico's en het belang van beschikbaar hulpaanbod [4] zijn mogelijkheden voor preventieve ondersteuning voor deze scheidingskinderen in Nederland beperkt $[5,6]$. Het aanbod is erg versnipperd, lokaal georganiseerd, en vooral gericht op kinderen vanaf 8 jaar. Voorbeelden zijn de groepsinterventies KIES (Kinderen in EchtscheidingsSituaties) en !JES het- brugproject (Jij en Scheiden) die staan beschreven in de databank Effectieve Jeugdinterventies van het Nederlands Jeugdinstituut (www.nji.nl/jeugdinterventies). Onderbouwd preventief aanbod voor met name jonge kinderen is daarom gewenst. Het Children of Divorce Intervention Program (CODIP) [7] is een evidencebased groepsinterventie gericht op preventie van scheidingsgerelateerde problematiek. Dit artikel gaat over een pilotstudie naar Dappere Dino's 2.0 dat gebaseerd werd op CODIP, in vervolg op een Nederlandse haalbaarheidsstudie naar dit groepsprogramma [8].

\section{CODIP en Dappere Dino's}

CODIP is in internationaal onderzoek effectief gebleken met betrekking tot de preventie van zowel internaliserende als externaliserende problematiek (voor een overzicht zie CODIP in National Registry of Evidence-based Programs and Practices op www.nrepp.samhsa.gov). 
CODIP bestaat uit verschillende leeftijdsspecifieke modules. In samenwerking met praktijkpartners heeft de Nederlandse Organisatie voor Toegepast Natuurwetenschappelijk Onderzoek (TNO) voor kinderen van 6 tot en met 8 jaar een Nederlandse bewerking gemaakt die aansluit bij deze leeftijdsgroep, genaamd Dappere Dino's. In 12 wekelijkse groepsbijeenkomsten van 45 minuten wordt op speelse manier aandacht besteed aan het bespreken van scheidingsgerelateerde gevoelens, het leren omgaan met onrealistische percepties en attitudes ten aanzien van de scheiding, en het versterken van probleemoplossende vaardigheden van deelnemende kinderen.

In de groep worden veel creatieve materialen en spelvormen gebruikt zoals poppenspel, voorleesboeken, spelletjes, kaartjes en tekeningen. Aan het einde van iedere bijeenkomst krijgen kinderen een werkblad mee uit het 'Ik kan een heleboel'-boekje. De werkbladen zijn gekoppeld aan de inhoud van de bijeenkomsten. Het boekje is een mogelijke manier om de brug te slaan tussen de training en de thuissituatie van het kind: het kind oefent en de ouder kan ondersteunen. Ouders worden verder geïnformeerd en betrokken, tijdens de individuele intake, op een facultatieve groepsbijeenkomst, middels nieuwsbrieven en bij de individuele eindevaluatie.

In samenwerking met Stichting De Jutters, Centrum voor Jeugd-GGZ Haaglanden en Centrum Autisme Rivierduinen vond eerder reeds een haalbaarheidsstudie plaats naar de introductie van Dappere Dino's in de Nederlandse setting. Dappere Dino's versie 1.0 (toen nog 15 sessies) werd geëvalueerd in vier pilotgroepen. Het onderzoek werd in 2011 afgerond en liet veelbelovende resultaten zien [8]. De resultaten van deze haalbaarheidsstudie waren basis voor de erkenning van Dappere Dino's als theoretisch goed onderbouwd in de Databank Effectieve Jeugdinterventies van het Nederlands Jeugdinstituut. Op basis van de procesevaluatie in het onderzoek werd een definitieve versie van het programma samengesteld en voor het werkveld beschikbaar gemaakt. Deze versie 2.0 stond in de hier beschreven evaluatie centraal. Het doel was de haalbaarheid en effectiviteit van de aangepaste interventie vast te stellen. Daartoe werd een kleinschalige pilotstudie uitgevoerd.

\section{Methode}

\section{Design}

Deze pilotstudie bestond uit een procesevaluatie, gericht op de haalbaarheid en tevredenheid van gebruikers, en een effectevaluatie. De procesevaluatie omvatte het oordeel van kinderen, ouders en trainers, en de mate waarin het interventieprotocol werd gevolgd. De effecten van Dappere Dino's zijn nagegaan door een voor- en nameting onder trainers, leerkrachten en (gezaghebbende) ouders van deelnemende kinderen. Op basis van een poweranalyse was vastgesteld dat met deelname van 21 kinderen, een effectgrootte van 0,64 (als gevonden in de haalbaarheidsstudie naar versie 1.0 [8]) aangetoond kan worden met een power van ,80 en een significantieniveau van ,05 (tweezijdig).

\section{Onderzoekspopulatie}

De afdeling Schoolmaatschappelijk Werk van Stichting Jeugdformaat heeft eenmalig een bericht uit laten gaan naar alle basisscholen in haar werkregio (regio Den Haag). Geïnteresseerde scholen konden kosteloos gebruikmaken van Dappere Dino's als onderdeel van de pilotstudie gefinancierd door Stichting Kinderpostzegels Nederland. Er vonden uiteindelijk vijf Dappere Dino's groepjes plaats met respectievelijk twee, zes, vier, zes en drie deelnemers, elk begeleid door één van twee gecertificeerde Dappere Dino's trainers en een co-trainer. Verder is een Dappere Dino's groep (vijf deelnemers) uitgevoerd in het kader van een ZonMw VIMP (Verspreidings- en Implementatie Impuls) [9], begeleid door twee gecertificeerde Dappere Dino's trainers van Stichting Jonge Helden. Dit maakt het totaal aantal deelnemers waarover gerapporteerd wordt 26 .

Deelnemers waren kinderen van ouders die in de afgelopen drie jaar gescheiden zijn, voor wie scheiding een actueel thema was, in de leeftijd van zes tot en met acht jaar (groep 3-5 van de basisschool). Alle ouders werd gevraagd een toestemmingsverklaring te tekenen voor deelname aan het onderzoek en de interventie. Hetzelfde onderzoeksprotocol werd gevolgd zoals eerder door de medisch-ethische toetsingscommissie goedgekeurd voor de haalbaarheidsstudie naar versie 1.0.

\section{Meetinstrumenten}

Het interventieproces werd geëvalueerd middels een logboekje dat trainers na iedere sessie invulden. In dit voorgestructureerde logboekje benoemden de trainers onder andere in hoeverre de doelen van de bijeenkomst behaald waren, welke werkwijzen waren uitgevoerd en welke materialen werden gebruikt. Er stonden ook evaluatievragen in de vragenlijst van de trainers op de nameting. Verder beantwoordden ook ouders evaluatieve vragen over de interventie op de nameting. Deze evaluatievragen zijn ingevuld door 20 moeders en 13 vaders. Na deelname aan Dappere Dino's vond een evaluatiegesprek plaats met alle deelnemende kinderen.

Om de uitkomsten van de interventie te evalueren gebruikten we vijf bestaande vragenlijsten, ingevuld door trainers, leerkrachten en ouders. Aan ouders van alle kinderen bij wie geïnformeerde toestemming werd verkregen, is direct gevraagd om de Strengths and Difficulties Questionnaire (SDQ) Parent Form (SDQ PF) [10] en een Parent Evaluation Form [11] bij wijze van voormeting in te vullen. Die meting is herhaald na afloop van de interventie (na sessie 12). Trainers kennen de kinderen bij aanvang van Dappere Dino's pas kort. Om een goede inschatting van psychosociaal functioneren te kunnen 
maken, vulde de trainer de Group Leader Evaluation Form (GLEF) [11] en SDQ Teacher Form (TF; per kind) in bij wijze van voormeting na de vierde sessie. Dit is conform onderzoek in de VS en het pilotonderzoek naar de eerste versie van Dappere Dino's [8]. Deze meting werd door de trainer herhaald na afloop van de laatste sessie. De leerkracht (van ieder deelnemend kind afzonderlijk) werd, zoals de ouders bij aanvang en na afloop van de sessies, gevraagd de SDQ TF in te vullen.

\section{Analyses}

Gepaarde t-testen zijn uitgevoerd voor het meten van een verschil tussen de voor- en nameting op genoemde vragenlijsten. We hanteerden een statistisch significantieniveau van ,05 (tweezijdig). De power van ons onderzoeksdesign is te beperkt om kleine tot middelgrote effecten aan te tonen, daarom presenteren we daarnaast verschillen met een significantieniveau van ,10 (gelijk aan een eenzijdig significantieniveau van ,05) als trends in onze uitkomsten.

Het gebruik van effectgroottes (Cohen's $d$ [12]) schept de mogelijkheid om de grootte van verschillen tussen voor- en nametingen inzichtelijk te maken, naast, of in aanvulling op, hoe statistisch significant ze zijn. De berekende effectgrootte is het verschil tussen twee gemiddelden, uitgedrukt in aantal standaarddeviaties van de data, en gecorrigeerd voor de correlatie tussen de gemiddelden. Positieve waarden duiden op een verbetering van de resultaten van de interventie in de tijd. Een (absolute) effectgrootte van 0,00 duidt op geen effect, een $d$ tussen 0,20 en 0,50 op een klein effect, $d$ tussen 0,50 en 0,80 op een middelgroot effect, en een $d$ van 0,80 of hoger op een groot effect [12].

\section{Resultaten}

\section{Resultaten procesevaluatie}

Alle kinderen die deelnamen aan Dappere Dino's vonden het programma leuk en vonden het fijn om in de groep over hun gevoelens te praten. Ze gaven aan nieuwe vrienden te hebben gemaakt en te hebben geleerd over hun gevoelens te praten en problemen op te kunnen lossen. De trainers werkten graag met de interventie: ze waren positief over het algemene verloop van de sessies en vonden de afwisseling van de verschillende werkvormen binnen de sessies erg prettig. Het aantal sessies en de duur ervan werden positief geëvalueerd.

Tachtig procent van de moeders (16 van 20 ) zag een positieve verandering in gevoelens en/of gedrag van hun kind sinds het begin van Dappere Dino's. Dappere Dino's had verheldering gegeven, kinderen waren meer open geworden (meer praten/gevoelens uiten) of waren rustiger na deelname aan de interventie. De meerderheid van de moeders (17 van 20) benoemde bovendien positieve reacties van de kinderen op het bijwonen van de bijeen- komsten (bijvoorbeeld "Hij kwam altijd met verhalen thuis na de Dappere Dino's. Hij voelde zich daar fijn"). De begeleiding door de trainers en de inhoud van het programma werden door de moeders het meest gewaardeerd. Moeders die op de ouderavond aanwezig waren $(n=13)$, vonden deze nuttig. Ook de nieuwsbrieven werden positief geëvalueerd. Op de vraag wat moeders het meest gemist hebben tijdens de Dappere Dino's, hebben 14 van de 20 moeders ofwel niets ingevuld ofwel niets gemist. Twee moeders hadden nog wel meer informatie over hun kind willen ontvangen. Drie moeders hadden andere gedachten over ouderbetrokkenheid ("Misschien nog een afspraak met de ouders om ons bij te brengen hoe we het beste met onze kinderen over de scheiding moeten/kunnen praten", en "Een één-op-één-gesprek met begeleider (zonder ex erbij dus)." Eén ouder gaf aan diepgang gemist te hebben.

De ervaringen van vaders zijn grotendeels gelijk aan die van moeders.

\section{Resultaten effectevaluatie}

Volgens de door de trainers ingevulde vragenlijsten was er een statistisch significante toename in positief functioneren van de deelnemende kinderen tussen de voor- en nameting (GLEF; $d=0,61 ; p<, 01$ ).

In Figuur 1 zijn de gemiddelde effectgroottes weergegeven voor het verschil tussen voor- en nameting op de SDQ vragenlijsten door trainers, leerkrachten, moeders en vaders. De trainers rapporteerden over 26 kinderen, en, door ontbrekende waarden, rapporteerden leerkrachten over 18 kinderen, moeders over 19 en vaders over 13 kinderen. In de figuur is markering aangebracht voor kleine, middelgrote en grote effecten.

Trainers rapporteerden afgenomen emotionele problemen (SDQ TF; $p<, 05, d=0,49$ ), en gedragsproblemen na deelname (statistische trend; $p<, 10, d=0,44$ ). Op basis van de rapportage door de leerkrachten leken deelnemende kinderen na deelname minder emotionele problemen te hebben dan ervoor $(p<, 10, d=0,41)$. We zagen kleine afnames in leerkrachtgerapporteerde gedragsproblemen, hyperactiviteit en totale problemen $(d>0,20)$, en een kleine toename in problemen met leeftijdsgenoten $(d<-0,20)$, maar deze verschillen waren niet statistisch significant. Moeders rapporteerden afnames in emotionele problemen (SDQ PF; $p<, 05, d=0,56$ ), gedragsproblemen $(p<, 10, d=0,50)$, en totale problemen $(p<, 05, d=0,76)$. Voor vaders bereikte geen van de verschillen tussen de voor- en nameting statistische significantie. Verder duidde vergelijking van ouder-gerapporteerd positief functioneren van de kinderen (PEF) op de voor- en nameting op een kleine (vaders; niet significant, $d=0,48$ ) tot middelgrote (moeders; $p<, 05, d=0,56$ ) toename. 


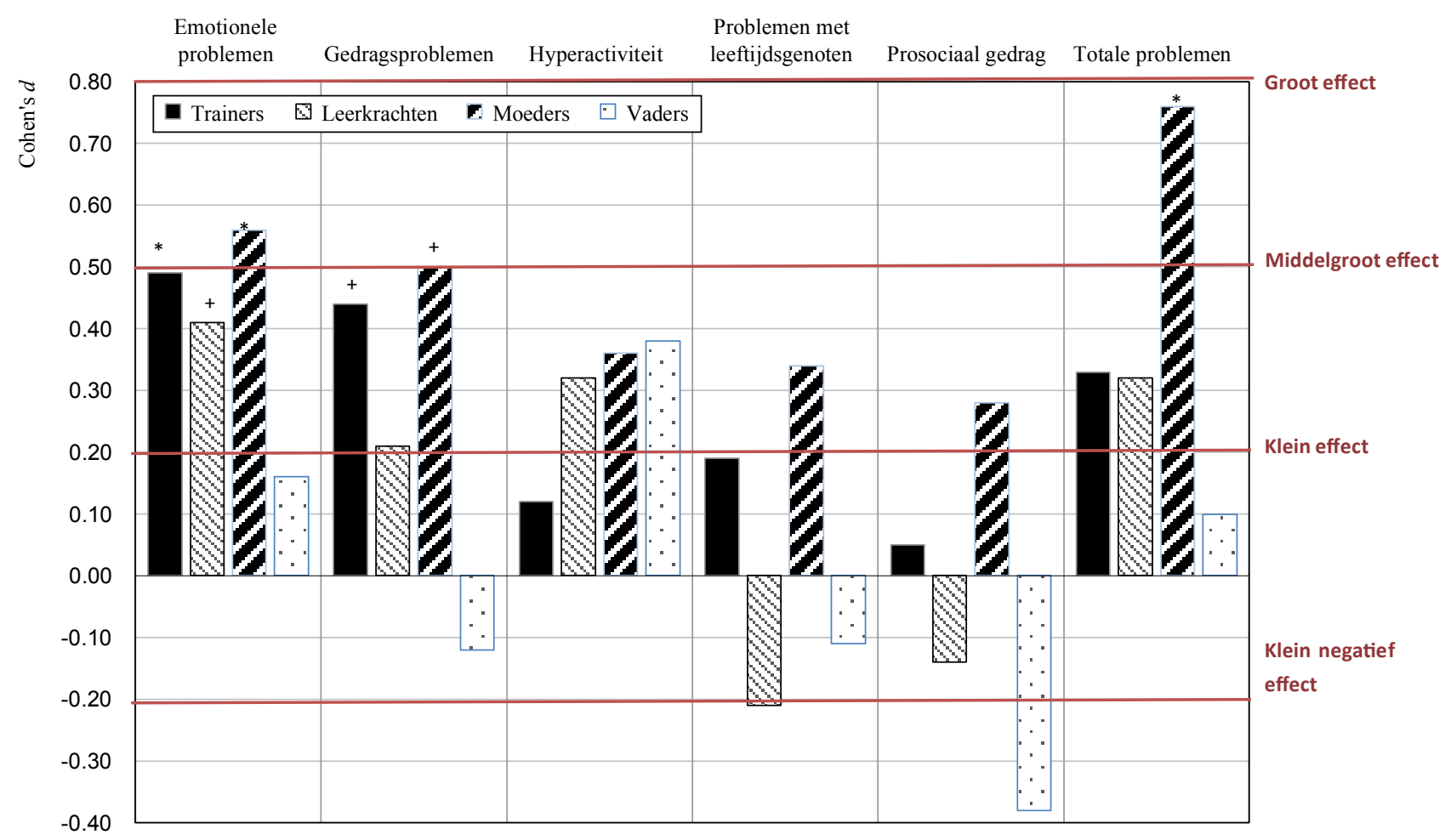

Figuur 1 Gemiddelde effectgroottes voor het verschil tussen voor- en nameting op de SDQ TF en PF door de trainers ( $n=26)$, leerkrachten $(n=18)$, moeders $(n=19)$ en vaders $(n=13)$. Nota bene. ${ }^{*} p<, 05$ (tweezijdig); en, ${ }^{+} p<, 10$ (trends).

\section{Discussie en conclusie}

Op basis van de procesevaluatie is gebleken dat de nieuwe praktijkversie 2.0 van de interventie Dappere Dino's haalbaar is, gebaseerd op het oordeel van kinderen, trainers en ouders, en de mate waarin het interventieprotocol gevolgd kan worden. Kinderen, trainers en ouders waren enthousiast over het huidige programma.

De resultaten van de effectevaluatie duiden op een verbetering in psychosociaal functioneren, en een afname in emotionele problemen, gedragsproblemen en totale problemen, gemeten met vragenlijsten, door middel van een voor- en nameting, onder trainers, leerkrachten en ouders. De door trainers gerapporteerde verbetering in psychosociaal functioneren is kleiner dan in de eerdere studie naar de eerste versie van Dappere Dino's $(d=1,03)$ [8] en het Amerikaanse onderzoek $(d=1,44)$ [11], maar betreft wel een middelgrote toename $(d=0,61)$. De door moeders gerapporteerde verbetering in psychosociaal functioneren is groter dan in de eerste haalbaarheidsstudie $(d=0,39)$ [8] en vergelijkbaar met het Amerikaanse onderzoek $(d=0,64)$ [11]. Op basis van de bescheiden, maar veelbelovende resultaten lijkt het mogelijk om met de interventie succesvol bij te dragen aan de preventie dan wel vermindering van (scheidingsgerelateerde) problematiek van deelnemende kinderen.

Het huidige onderzoek was beperkt door een kleine steekproefgrootte, afwezigheid van een controlegroep en geen beschikbaarheid van geblindeerde informan- ten. De power van de analyses was beperkt. Toch vonden we belangrijke aanwijzingen voor de effectiviteit van de interventie in de vorm van een aantal positieve, klein tot middelgrote, statistisch significante verschillen tussen de voor- en nameting, op basis van meerdere informanten (trainers, leerkrachten en moeders).

De gevonden resultaten zijn een mooi uitgangspunt voor voortgaand effectonderzoek naar de uitkomsten van de interventie en voor verdere implementatie van de interventie in de praktijk. Ze vormen eerste aanwijzingen voor de haalbaarheid van toepassing van deze tweede versie van de interventie, gegeven de tevredenheid van intermediaire gebruikers en eindgebruikers. Bovendien lijkt het haalbaar om een aantal positieve effecten zoals eerder gevonden in de VS, ook in de Nederlandse praktijk te bewerkstelligen. TNO ontving in 2012 subsidie van ZonMw om ook voor de leeftijdsgroep van 4 tot en met 6 jaar een groepsprogramma op te zetten en te evalueren. Deze interventie heet Stoere Schildpadden en ook hiervoor vormt het Amerikaanse CODIP de basis. TNO startte bovendien in 2015 nieuw effectonderzoek naar Dappere Dino's (gesubsidieerd door ZonMw in het kader van het Nationaal Preventieprogramma Alles is Gezondheid). Het betreft een quasi-experimenteel onderzoek met een passende controlegroep. Toekomstig effectonderzoek kan meer inzicht bieden in de effectiviteit van Dappere Dino's en Stoere Schildpadden: voor wie werkt het het beste, in welke contexten onder welke omstandigheden? 


\section{Dankbetuiging}

Dit onderzoek werd mede mogelijk gemaakt door subsidies van Stichting Kinderpostzegels Nederland (project 7598097) en ZonMw (dossier 15700.0950.05). Wij danken Schoolmaatschappelijk Werk van Stichting Jeugdformaat en Stichting Jonge Helden voor de samenwerking in dit onderzoek.

\section{Literatuur}

1. Spruijt E. Scheidingskinderen: overzicht van recent sociaal-wetenschappelijk onderzoek naar de gevolgen van ouderlijke scheiding voor kinderen en jongeren. Amsterdam: SWP; 2007.

2. Amato PR, James S. Divorce in Europe and the United States: commonalities and differences across nations. Fam Sci. 2010;1:2-13.

3. Amato PR, Keith B. Parental divorce and the well-being of children: a meta-analysis. Psychol Bull. 1991;110(1):26-46.

4. FamiliesAndSocieties. Solomonic choices: parental separation, child well-being and family policies in Europe. European Policy Brief, March 2014. 2014. http://ec.europa.eu/ research/social-sciences/policy-briefs_en.html. Accessed 10 April 2014.

5. Cloostermans A, Klein Velderman M, Pannebakker F. Aanbod relatieondersteuning en preventie van scheidingsgerelateerde problematiek bij kinderen in noordelijk Zuid-Holland. Leiden: TNO Behavioural and Societal Sciences;2013. TNO/CH 2013 R10709

6. Vermeij A, Van der Wel J, Krooneman PJ. Inventarisatie hulpaanbod bij (echt)scheiding en omgang: eindrapport. $2005 ; 1380$.
7. Pedro-Carroll J, Jones SH. A preventive play intervention to foster children's resilience in the aftermath of divorce. In: Reddy LA, Files-Hall TM, Schaefer CE, editors. Empirically based play interventions for children. Washington: APA; 2005. P. 51-75.

8. Klein Velderman M, Pannebakker FD, Wolff MS De, PedroCarroll JA, Kuiper RM, Vlasblom E, et al. Child adjustment in divorced families: can we successfully intervene with Dutch 6- to 8-year-olds? Feasibility study Children of Divorce Intervention Program (CODIP) in the Netherlands. The Netherlands: TNO; 2011. TNO/CH 2011.031.

9. Klein Velderman M, Cloostermans APG, Pannebakker FD. De implementatie van Dappere Dino's: groepsprogramma voor kinderen van 6-8 jaar van gescheiden ouders. Verslag van een ZonMw Verspreidings- en Implementatie Impuls (VIMP). Leiden: TNO Behavioural and Societal Sciences; 2014.

10. Goodman R. The strengths and difficulties questionnaire: a research note. J Child Psychol Psychiatry. 1997;38:581-6.

11. Alpert-Gillis LJ, Pedro-Carroll JL, Cowen EL. Children of divorce intervention program: development, implementation and evaluation of a program for young urban children. J Consult Clin Psychol. 1989;57:583-7.

12. Cohen J. Statistical power analysis for the behavioral sciences. Hillsdale: Lawrence Erlbaum Associates; 1969.

\section{Klein Velderman, onderzoeker TNO}

F.P. Pannebakker, onderzoeker TNO

S.A. Reijneveld, hoogleraar Sociale Geneeskunde 